\title{
A model synthetic approach towards the furanacetal component of azadirachtin: a potent insect antifeedant
}

\author{
Sushil Raina, B. A. Bhanu Prasad, and Vinod K. Singh* \\ Department of Chemistry, Indian Institute of Technology, Kanpur, India - 208016 \\ E-mail: vinodks@iitk.ac.in
}

Dedicated with respect to Professor Sukh Dev on his $80^{\text {th }}$ birthday

(received 30 Sep 02; accepted 16 Dec 02; published on the web 03 Jan 03)

\begin{abstract}
In this article, a model synthetic approach towards the furanacetal component of azadirachtin has been described from $\alpha$-D-glucose. Tandem radical cyclization was the key step for the formation of the desired tricyclic system. The reaction provided a bicyclic system instead of the desired tricyclic molecule. The reason for the unsuccessful tandem cyclization was proposed to be mainly energy factors.
\end{abstract}

Keywords: $\alpha$-D-glucose, azadirachtin, tandem radical cyclization

\section{Introduction}

The fused cyclic acetal moiety is embodied in a large number of natural products many of which display interesting biological properties, ranging from the highly toxic and carcinogenic aflatoxins $^{1}$ to insect antifeedants such as clerodin ${ }^{2}$ and azadirachtin $\mathbf{1}$. The furo[2,3b]pyran unit is conserved in the azadirachtin, whilst several clerodanes and aflaxtoxins contain the more common furo[2,3b]furan moiety. Many methods exist for the synthesis of the furo[2,3b]furans. ${ }^{3}$ In contrast, relatively few synthesis of the homologous furo[2,3b]pyrans have been reported. ${ }^{4}$ We wished to develop and work out a much flexible and relatively shorter route of the bioactive portion of the most potent insect antifeedant azadirachtin. Azadirachtin ${ }^{5}$ belongs to the C-secolimonoid group of triterpinoids and is found in neem tree, or Indian lilac, Azadirachta indica. Although the first synthesis of the $\mathbf{1}$ is yet to be accomplished, nevertheless the biological testing has so far relied upon the natural azadirachtin, their chemically modified fragments, and a few synthetic analogs. The simple compounds $\mathbf{2}$ and $\mathbf{3}$, components of the $\mathbf{1}$, have been synthesized and screened for antifeedant activity. ${ }^{6}$ Both of these compounds were found to be active against African leaf worm Spodoptera lottoralis. The compound $\mathbf{3}$ was found to be as potent as the natural product 1 itself at $10 \mathrm{ppm}$ and $1 \mathrm{ppm}$ concentrations. This finding suggested that the 
dihydrofuranacetal moiety of the azadirachtin is mainly responsible for its biological activity and therefore stimulated synthesis of both the racemic and enatiomerically pure dihydrofuranacetal analogs.

Shibasaki and coworkers ${ }^{7}$ have synthesized an intermediate which closely resembles the dihydrofuranacetal portion of $\mathbf{1}$ during their efforts directed towards its total synthesis starting from (S)-(-) ethyl lactate. The contribution of Ley and coworkers in the structure determination of azadiractin, synthesis of important intermediates and analogs, and their bioevaluation is unsurmountable. ${ }^{6 a, 8}$ Starting from a 3,4-O-isopropylidenegalactal, ${ }^{9,10}$ Fraser-Reid and
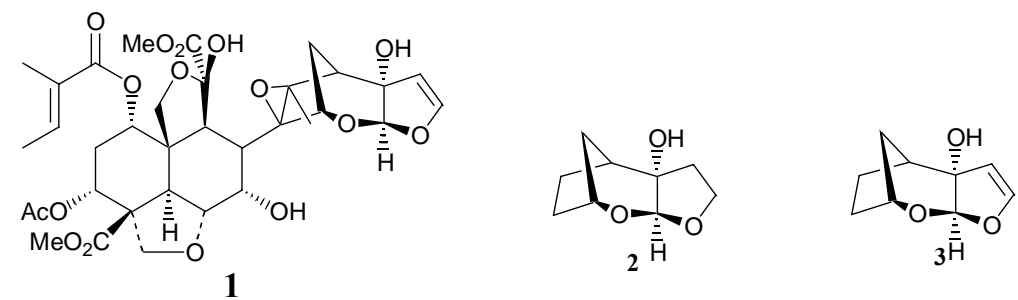

coworkers $^{11}$ have been able to synthesize a dihydrofuranacetal analog in $7.7 \%$ overall yield in 17 steps. In this paper, we discuss full details of model synthetic studies on the tricyclic dihydrofuranacetal moiety of azadirachtin from $\alpha$ - D-glucose.

\section{Results and Discussion}

Ley's report that the structural fragment $\mathbf{3}$ is as active an insect antifeedant as azadirachtin itself prompted us to design a flexible synthetic route to this portion so that simpler analogs could be synthesized. With this aim, a strategy based on an $\alpha, \beta$-unsaturated lactone and the corresponding lactol of the required number of carbon atoms as important intermediates was conceived. In retrosynthetic analysis, as shown in scheme $\mathbf{I}$, the key step would be a tandem radical cyclization $^{12}$ in which the tricyclic framework would be formed in one step and provide a handle for the synthesis of analogs. The internal carbon of the propargyl function would act as a nucleophilic radical for the tandem cyclization. Another important feature is the recognition of a partially-hidden carbohydrate symmetry in the target molecule, paving the way for a potential synthesis of the enatiomerically pure material. For the model study, we chose $\mathrm{X}_{1}=\mathrm{H}$ in structure 4. $\alpha$-D-glucose as the starting material for the synthesis of optically active target molecule 4 was identified. 

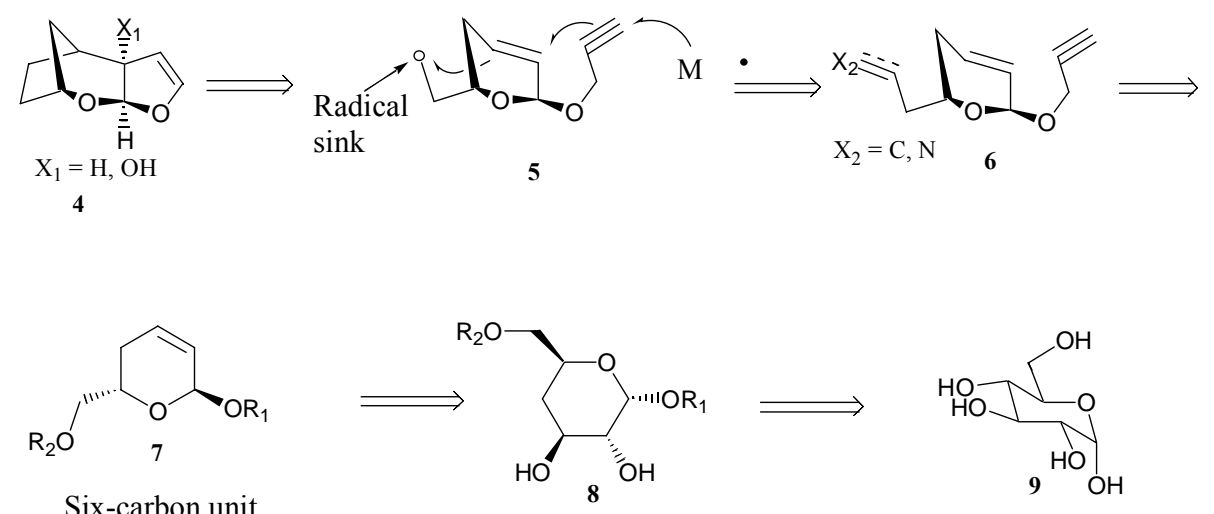

Scheme 1. Retrosynthetic analysis.

Over the years carbohydrates have been recognized as naturally occurring organic molecules that are relatively cheap and replenishible source of cyclic and acyclic forms, chain lengths and oxidation or reduction states. They are endowed with a wealth of stereochemical attributes and contain a plethora of functional groups available for chemical exploitation. ${ }^{13} \alpha$-D-Glucose 9 is one of the simplest and cheapest carbohydrates used in innumerable syntheses. $\alpha$-D-glucose was recognized as an ideal starting material for the synthesis because of several reasons. Firstly, the chirality of anomeric center and C-5 carbon atom of the 9 is preserved in the final molecule. Secondly, the possibility of generation of an olefin in the ring as it is in the molecule 7 from the hydroxyl groups at C-2 and C-3. And thirdly, the advantage offered by the hydroxyl group at C-4 of the 9, which can either be dehydroxylated or preserved for analog preparation. In the compound 7, exchange of anomeric center with propargyl alcohol and one carbon extension in the side chain via $\mathrm{S}_{\mathrm{N}} 2$ displacement by cyanide anion at C-6 offered a simple strategy for the synthesis of the $\mathbf{6}$, a substrate for tandem radical cyclization.

For the synthesis of the 2,3-unsaturated propargyl glucoside $\mathbf{1 3}$ or its acetate derivative, we required tri-O-acetyl-D-glucal in large quantities. Tri-O-acetyl-D-glucal 10, which is inexpensively and readily available from $\alpha$-D-glucose, was prepared according to the literature procedure. $^{14} \alpha$-D-glucose was peracetylated to penta- $O$-acetyl- $\alpha$-D-glucose which was, then, converted to the corresponding tetra- $O$-acetyl- $\alpha$-D-glucosyl bromide using red phosphorus and bromine. Glycosyl bromide was reduced, in situ to tri- $O$-acetyl- $\alpha$-D-glucal 10 which was hydrolysed to glucal 11 using a catalytic amount of sodium methoxide in methanol. The primary hydroxyl group in the glucal $\mathbf{1 1}$ was selectively tosylated and the secondary hydroxyl groups were, then, acetylated to obtain a new glucal 12 in one pot. ${ }^{14 b, 15}$ Then the glucal 12 was treated with propargyl alcohol in the presence of $\mathrm{BF}_{3} . \mathrm{Et}_{2} \mathrm{O}$ in chloroform at a low temperature to obtain propargyl glucoside 13. The tosylate group of the $\mathbf{1 3}$ was displaced by cyanide ion by heating it with sodium cyanide in DMSO at a moderate temperature. During this process, the acetate group also hydrolyzed. The compound 14, thus obtained, was reacetylated to afford $\mathbf{1 5}$. The framework of the $\mathbf{1 5}$ was of the type $\mathbf{6}$, and was ready for tandem free radical cyclization (Scheme II). 

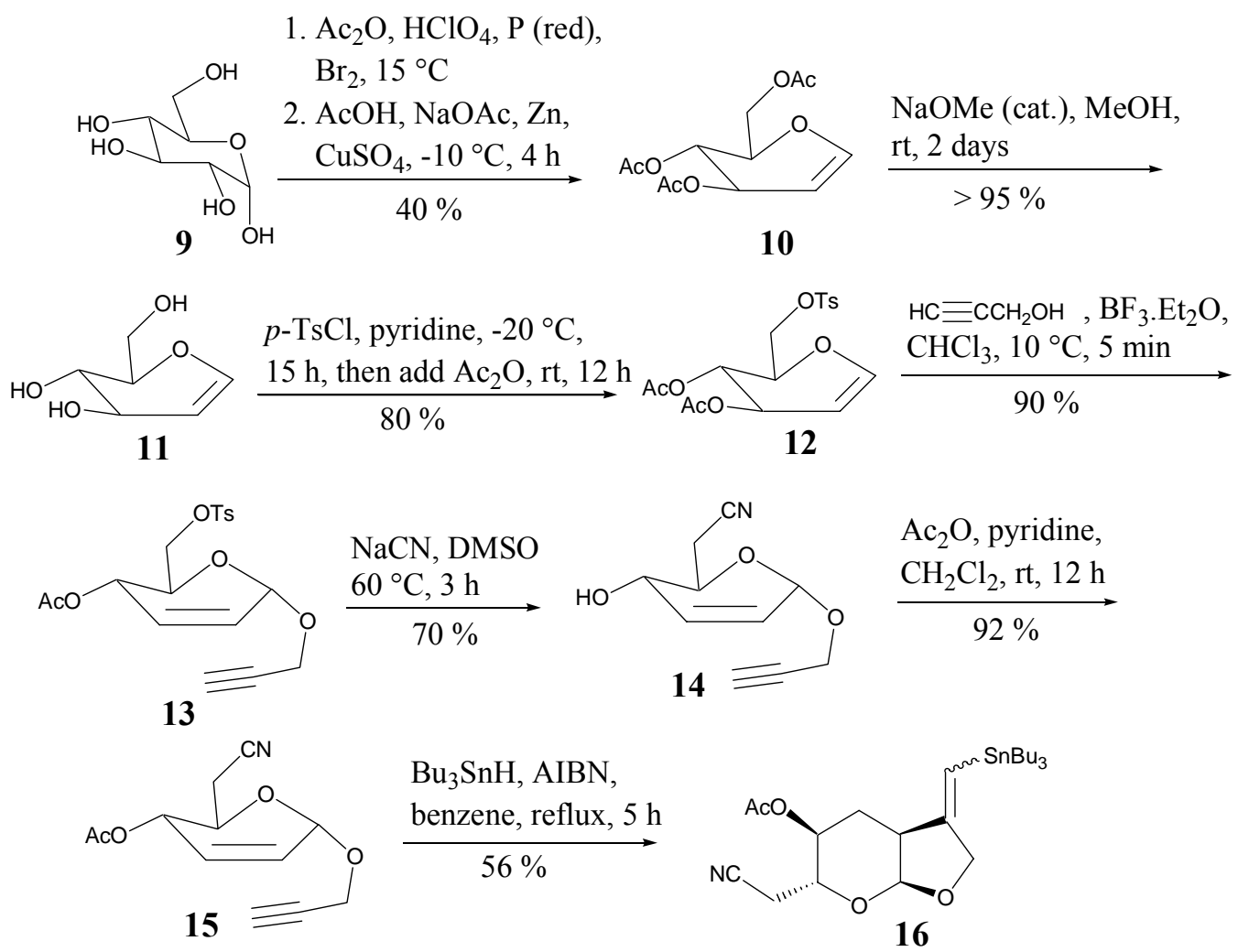

\section{Scheme 2}

At this stage, the substrate $\mathbf{1 5}$ was to be subjected to tributyltin hydride mediated radical cyclization to obtain the desired tricyclic product of the type $\mathbf{4}$ as planned in the retrosynthetic scheme. The reaction was expected to undergo tandem cyclization. The addition of the tributyltin radical onto the terminal triple bond would result in the generation of vinylic radical, which could cyclise to form the $\mathrm{C}-\mathrm{C}$ bond. ${ }^{16}$ Similar kind of reactions are well known in the literature. ${ }^{17}$ Although nitriles are not efficient radical acceptors, there are examples in the literature where radical species have been added to nitriles to produce iminium radicals, which then are hydrolyzed to the corresponding ketones. ${ }^{18}$ However, the drawback of the reaction is that the intermediate iminium radical easily reverts back if the molecular strain demands and, also, they can rearrange to nitrile stabilized carbon radicals which then react further. ${ }^{19}$ With the above background we treated the substrate $\mathbf{1 5}$ with tributyltin hydride in the presence of a catalytic amount of AIBN in degassed benzene at reflux for $5 \mathrm{~h}$. Unfortunately, the cyclization stopped at a bicyclic stage and a compound 16 (furo-pyran) was obtained as the sole product (scheme II). The radical cyclization from ring to the nitrile group could not be realized to obtain the desired tricyclic system.

The possible reason for the failure of tricyclic product formation was thought to be a considerable energy difference between the intermediate depicted by $\mathbf{1 7 a}$ and $\mathbf{1 7 b}$ in scheme III. The conformation necessary for the reacting centers to come in to close proximity for the $\mathrm{C}-\mathrm{C}$ 
bond formation is $\mathbf{1 7 b}$, and a small portion of it in this equilibrium would have been sufficient for the tandem cyclization. But the presence of all equatorial substituents and the anomeric stabilization in the representation $\mathbf{1 7} \mathbf{a}$ prevented the ring flip to attain the conformation $\mathbf{1 7} \mathbf{b}$ to an extent that no

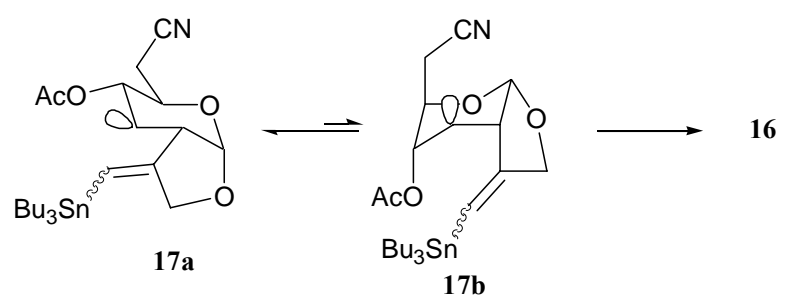

\section{Scheme 3}

double cyclization resulted. Further modifications of the schemes are continuing in our laboratory and will be disclosed elsewhere in future.

In conclusion, we have analysed the retrosynthesis of the biologically active portion of the most potent insect antifeedant viz. azadirachtin in a conceptually different manner based on the tandem radical cyclization reactions leading to the relatively simple routes for the analog preparation in optically pure form from $\alpha$-D-glucose.

\section{Experimental Section}

3,4,6-Tri-O-acetyl-D-glucal (10). $\alpha$-D-Glucose $(60 \mathrm{~g}, 0.33 \mathrm{~mol})$ was added to a mixture of acetic anhydride $(200 \mathrm{~g}, 1.96 \mathrm{~mol})$ and $70 \%$ perchloric acid $(1.2 \mathrm{~mL})$ at $35{ }^{\circ} \mathrm{C}$ during $1 \mathrm{~h}$. After addition of red phosphorus (15 g, $0.48 \mathrm{~mol}$ ), the vessel was cooled in ice-salt mixture, and bromine ( $90 \mathrm{~g}, 0.56 \mathrm{~mol}$ ) was added dropwise with continued stirring at such a rate as to keep the internal temperature below $20^{\circ} \mathrm{C}$. Subsequently in the same way, $15 \mathrm{~mL}$ of water was added during a course of $30 \mathrm{~min}$ with careful control of temperature. The mixture was filtered and the filter paper washed with little acetic acid. The filtrate contained tetra- $O$-acetyl- $\alpha$-Dglucopyranosyl bromide. Meanwhile a solution of sodium acetate (160 g, $1.95 \mathrm{~mol})$ in water $(250 \mathrm{~mL})$ and glacial acetic acid $(200 \mathrm{~mL})$ was prepared. After the solution was cooled in an icesalt mixture, zinc dust $(110 \mathrm{~g}, 1.68 \mathrm{~mol})$ and cupric sulfate $(11 \mathrm{~g}, 0.04 \mathrm{~mol})$ in water $(40 \mathrm{~mL})$ were added to this solution. When the blue color had disappeared, the solution of abovementioned bromide was added gradually during $1 \mathrm{~h}$ keeping the temperature between -10 and $20{ }^{\circ} \mathrm{C}$. Efficient stirring was necessary and was continued for $3 \mathrm{~h}$ at $0{ }^{\circ} \mathrm{C}$. The mixture was filtered, and the filter paper was washed with $50 \%$ acetic acid. Water $(500 \mathrm{~mL})$ was added to the combined filtrates at $0{ }^{\circ} \mathrm{C}$ and the solution was extracted with chloroform $(5 \mathrm{x} 100 \mathrm{~mL})$. The combined chloroform extracts were washed with iced-water, saturated sodium carbonate solution, and again with cold-water. The solution was dried by addition of calcium chloride, decanted, and evaporated under reduced pressure. The resulting syrup was dissolved in diethyl 
ether and petroleum ether was added to the solution to opalescence. Seed aided crystallization provided pure 10 ${ }^{14}$ (45 g, 40\%); mp $55^{\circ} \mathrm{C}$, lit. ${ }^{20} 53-55^{\circ} \mathrm{C} ;[\alpha]_{\mathrm{D}}^{25}-12.0$ (c 2, EtOH); IR (film) $1740,1640 \mathrm{~cm}^{-1} ;{ }^{1} \mathrm{H}$ NMR $\left(60 \mathrm{MHz}, \mathrm{CDCl}_{3}\right) \delta 1.6-2.26(\mathrm{~m}, 9 \mathrm{H}), 4.03-4.57(\mathrm{~m}, 3 \mathrm{H}), 4.73-$ $4.97(\mathrm{~m}, 1 \mathrm{H}), 5.07-5.50(\mathrm{~m}, 2 \mathrm{H}), 6.47(\mathrm{~d}, J=6 \mathrm{~Hz}, 1 \mathrm{H})$.

Glucal (11). To a stirred solution of $10(10 \mathrm{~g}, 36.73 \mathrm{mmol})$ in dry methanol $(100 \mathrm{~mL})$ was added methanolic solution of sodium methoxide (prepared by dissolving $50 \mathrm{mg}$ of sodium in $2 \mathrm{~mL}$ methanol), and the solution was left at room temperature for 2 days. Evaporation of the solvent gave crystalline $11^{35}$ in quantitative yield, which was used as such for subsequent steps; $\mathrm{mp} 56$ $58{ }^{\circ} \mathrm{C}$, lit. ${ }^{14} 57-59{ }^{\circ} \mathrm{C} ;[\alpha]^{25}$ D -8.3 (c $\left.2, \mathrm{H}_{2} \mathrm{O}\right)$, lit. $^{14}[\alpha]_{\mathrm{D}}^{25}-8$ (c 1.9, $\left.\mathrm{H}_{2} \mathrm{O}\right)$; IR (film) $3290 \mathrm{~cm}^{-1}$; ${ }^{1} \mathrm{H}$ NMR $\left(60 \mathrm{MHz}, \mathrm{CD}_{3} \mathrm{OD}\right) \delta 3.23-3.46(\mathrm{~m}, 1 \mathrm{H}), 3.73-4.13(\mathrm{~m}, 3 \mathrm{H}), 4.23-4.50(\mathrm{~m}, 1 \mathrm{H}), 4.60$ - $5.0(\mathrm{~m}, 4 \mathrm{H}), 6.23-6.50(\mathrm{~m}, 1 \mathrm{H})$.

3,4-Di-O-acetyl-6-O-(p-toluenesulfonyl)-D-glucal (12). The $\alpha$-D-Glucal 11 (5 g, $34.2 \mathrm{mmol}$ ) was dissolved in a mixture of pyridine $(20 \mathrm{~mL})$ and dichloromethane $(10 \mathrm{~mL})$ and cooled to $-50{ }^{\circ} \mathrm{C}$. To this, a solution of $p$-toluenesulfonyl chloride $(7.82 \mathrm{~g}, 41 \mathrm{mmol})$ dissolved in dichloromethane $(20 \mathrm{~mL})$ was added in a dropwise fashion. The solution was stored at $-20{ }^{\circ} \mathrm{C}$ for $15 \mathrm{~h}$. Acetic anhydride $(10.5 \mathrm{~g}, 102.8 \mathrm{mmol})$ was added to the same pot at $0{ }^{\circ} \mathrm{C}$ and then allowed to stand at $\mathrm{rt}$ for $12 \mathrm{~h}$. The reaction mixture was then poured in ice-cold $2 \mathrm{~N} \mathrm{HCl}(100 \mathrm{~mL})$ and extracted quickly with chloroform $(5 \times 30 \mathrm{~mL})$. The combined organic layers were washed with saturated aqueous sodium bicarbonate, water and brine, dried over anhydrous sodium sulfate, filtered and evaporated to dryness. The silica gel chromatography provided $\mathbf{1 2}^{14 \mathrm{~b}, 15}(10.5 \mathrm{~g}, 80 \%)$ as a solid and approximately $10 \%$ of $\mathbf{1 0}$ as a side product; $R_{\mathrm{f}} 0.38$ (ethyl acetate in petroleum ether, 1: 3); $\mathrm{mp} 100{ }^{\circ} \mathrm{C}$, lit. ${ }^{15} 100-101{ }^{\circ} \mathrm{C} ;[\alpha]^{25} \mathrm{D}+15.8$ (c 0.945, CHCl3); IR (film) 3030, 1740, $1640,1590 \mathrm{~cm}^{-1} ;{ }^{1} \mathrm{H}$ NMR $\left(60 \mathrm{MHz}, \mathrm{CDCl}_{3}\right) \delta 2.00$ (s, 6H, OAc), 2.47 (s, 3H, benzylic), 4.03 $4.50(\mathrm{~m}, 3 \mathrm{H}), 4.83(\mathrm{dd}, J=6,3 \mathrm{~Hz}, 1 \mathrm{H}), 5.00-5.50(\mathrm{~m}, 2 \mathrm{H}), 6.37$ (d, $J=6 \mathrm{~Hz}, 1 \mathrm{H}), 7.33$ (d, $J=$ $8 \mathrm{~Hz}, 2 \mathrm{H}$, aromatic), 7.83 (d, $J=8 \mathrm{~Hz}, 2 \mathrm{H}$, aromatic).

Ethynemethyl 4-O-acetyl-2,3-dideoxy-6-(p-toluenesulfonyl)-a-D-erythro-hex-2-enopyranoside (13). To a solution of $12(1 \mathrm{~g}, 2.6 \mathrm{mmol})$ in chloroform $(10 \mathrm{~mL})$ at $0{ }^{\circ} \mathrm{C}$ were added propargyl alcohol (250 mg, $4.46 \mathrm{mmol})$ followed by $\mathrm{BF}_{3} \cdot \mathrm{Et}_{2} \mathrm{O}(180 \mathrm{mg}, 1.27 \mathrm{mmol})$ and allowed to warm to $10{ }^{\circ} \mathrm{C}$ over a period of $5 \mathrm{~min}$. A saturated solution of sodium bicarbonate was added and stirring continued for $5 \mathrm{~min}$. Extraction of the reaction mixture with chloroform $(3 \times 25 \mathrm{~mL})$, drying of the organic layers over anhydrous sodium sulfate and evaporation of the solvent under reduced pressure provided the crude product which was purified by silica gel chromatography to yield $\mathbf{1 3}$ $(890 \mathrm{mg}, 90 \%)$ as a liquid; $R_{\mathrm{f}} 0.21$ (ethyl acetate in petroleum ether, $\left.1: 4\right) ;[\alpha]_{\mathrm{D}}^{25}+100.8(c 0.60$, $\mathrm{CHCl}_{3}$ ); IR (film) 3248, 2910, 2120, $1720 \mathrm{~cm}^{-1} ;{ }^{1} \mathrm{H}$ NMR (60 MHz, CDCl 3 ) $\delta .2 .00$ (s, 3H, OAc), 2.37 (t, $J=3.5 \mathrm{~Hz}, 1 \mathrm{H}), 2.44$ (s, 3H, benzylic), $3.83-4.43(\mathrm{~m}, 5 \mathrm{H}), 4.93-5.40(\mathrm{~m}, 2 \mathrm{H})$, $5.70-6.10$ (m, 2H, olefinic), 7.36 (d, $J=8 \mathrm{~Hz}, 2 \mathrm{H}$, aromatics), 7.80 (d, $J=8 \mathrm{~Hz}, 2 \mathrm{H}$, aromatics). 
Ethynemethyl 6-cyano-2,3,6-trideoxy-a-D-erythro-hex-2-enopyranoside (14). The tosylate 13 (800 mg, $2.1 \mathrm{mmol})$ was dissolved in DMSO $(1 \mathrm{~mL})$ in a dry flask fitted with a guard-tube and dry sodium cyanide $(257 \mathrm{mg}, 5.25 \mathrm{mmol})$ was added to it. The contents were stirred at $60{ }^{\circ} \mathrm{C}$ for $3 \mathrm{~h}$, poured into cold water, and extracted with ethyl acetate $(5 \times 30 \mathrm{~mL})$. The organic layers were washed with brine, dried over anhydrous sodium sulfate and evaporated to dryness. The residue was chromatographed by silica gel column chromatography to provide pure 14 (284 $\mathrm{mg}$, $70 \%$ ) as a liquid; $R_{\mathrm{f}} 0.18$ (ethyl acetate in petroleum ether, 1: 3); IR (film) 3440, 3300, 2930, 2260, $2124 \mathrm{~cm}^{-1} ;{ }^{1} \mathrm{H}$ NMR $\left(60 \mathrm{MHz}, \mathrm{CDCl}_{3}\right) \delta 2.52(\mathrm{t}, J=2.2 \mathrm{~Hz}, 1 \mathrm{H}), 2.67-3.03(\mathrm{~m}, 2 \mathrm{H}), 3.40$ (bs, 1H, O프), $3.60-4.23(\mathrm{~m}, 2 \mathrm{H}), 4.33(\mathrm{~d}, J=2.2 \mathrm{~Hz}, 2 \mathrm{H}), 5.20(\mathrm{~d}, J=1 \mathrm{~Hz}, 1 \mathrm{H}), 5.60-6.20$ (m, 2H, olefinic).

Ethynemethyl 4-acetyl-6-cyano-2,3,6-trideoxy-a-D-erythro-hex-2-enopyranoside (15). The cyanoalcohol 14 (250 mg, $1.29 \mathrm{mmol})$ was dissolved in dichloromethane $(1 \mathrm{~mL})$ and pyridine (200 mg, $2.53 \mathrm{mmol})$ was added to it. After cooling to $0{ }^{\circ} \mathrm{C}$, acetic anhydride $(170 \mathrm{mg}, 1.67$ mmol) and a crystal of DMAP were added. The temperature was allowed to rise to rt and stirring continued for $12 \mathrm{~h}$. The contents of the flask were poured into cold dilute $\mathrm{HCl}$ and extracted into dichloromethane $(5 \times 25 \mathrm{~mL})$. The combined organic layers were washed with brine, dried over anhydrous sodium sulphate, and evaporated to dryness under reduced pressure. The purification over silica gel column provided pure $15(280 \mathrm{mg}, 92 \%)$ as a liquid; $R_{\mathrm{f}} 0.26$ (ethyl acetate in petroleum ether, 1:9); $[\alpha]_{\mathrm{D}}^{25}+150.9$ (c 0.80, $\mathrm{CHCl}_{3}$ ); IR (film) 3270, 3420, 2240, 2105, 1730 $\mathrm{cm}^{-1} ;{ }^{1} \mathrm{H}$ NMR $\left(60 \mathrm{MHz}, \mathrm{CDCl}_{3}\right) \delta 2.06(\mathrm{~s}, 3 \mathrm{H}, \mathrm{OAc}), 2.40(\mathrm{t}, J=2.4 \mathrm{~Hz}, 1 \mathrm{H}), 2.50-2.77(\mathrm{~m}$, 2H), $5.20-4.28(\mathrm{~m}, 1 \mathrm{H}), 4.33(\mathrm{~d}, J=2.4 \mathrm{~Hz}, 2 \mathrm{H}), 5.00-5.37$ (m, 1H), 5.80 (s, 2H, olefinic). Anal. Calcd. for $\mathrm{C}_{12} \mathrm{H}_{13} \mathrm{NO}_{4}$ : C, 61.27; H, 5.53; N, 5.95. Found: C, 61.40; H, 5.64; N, 5.84.

Cyclisation of 15 using $\boldsymbol{n}$-Bu $\mathbf{B}_{3} \mathbf{S n H}$. The nitrile 15 (100 $\left.\mathrm{mg}, 0.425 \mathrm{mmol}\right)$ was placed in benzene $(40 \mathrm{~mL})$ in a dry round-bottomed flask under an atmosphere of nitrogen and the reaction mixture was saturated with nitrogen. While refluxing, a solution of tributyltin hydride $(250 \mathrm{mg}, 0.85$ mmol) and AIBN (10 mg, catalytic), dissolved in benzene $(10 \mathrm{ml})$, was added to it using a syringe pump during a period of $5 \mathrm{~h}$. After the addition was complete, the reflux was continued for $1 \mathrm{~h}$. The solvent was evaporated under reduced pressure and the mixture was chromatographed on silica gel to give pure 16 as a liquid (129 mg, $56 \%$; a mixture of $\alpha$ - and $\beta$ isomers with $E$ - and $Z$-olefin $\alpha: \beta 4: 1 ; E: Z=4: 1$ ); $R_{\mathrm{f}} 0.67$ (ethyl acetate in petroleum ether, 1:9); IR (film) 2240, $1730 \mathrm{~cm}^{-1} ;{ }^{1} \mathrm{H}$ NMR (300 MHz, $\left.\mathrm{CDCl}_{3}\right) \delta 0.87-0.96(\mathrm{~m}, 15 \mathrm{H}), 1.24-1.34$ $(\mathrm{m}, 6 \mathrm{H}), 1.45-1.56(\mathrm{~m}, 6 \mathrm{H}), 1.62-1.70(\mathrm{~m}, 1 \mathrm{H}), 2.06-2.10(\mathrm{~m}, 3 \mathrm{H}), 2.23-2.33(\mathrm{~m}, 1 \mathrm{H}), 2.62$ $2.71(\mathrm{dd}, J=5.4,3.3 \mathrm{~Hz}, 2 \mathrm{H}), 2.73-2.84(\mathrm{~m}, 1 \mathrm{H}), 4.00-4.17(\mathrm{~m}, 1 \mathrm{H}), 4.19-4.32(\mathrm{~m}, 1 \mathrm{H}), 4.51$ - $4.63(\mathrm{~m}, 1 \mathrm{H}), 4.65-4.75(\mathrm{~m}, 1 \mathrm{H}), 5.28(\mathrm{~d}, J=3.9 \mathrm{~Hz}, 0.2 \mathrm{H}, \beta$-anomiric), 5.34 (d, J= $4.5 \mathrm{~Hz}$, $0.8 \mathrm{H}, \alpha$-anomeric), 5.58 - 5.74 (m, 0.2H, E-olefinic), 5.82 - 6.00 (m, 0.8H, Z-olefinic); MS (Fab, $\mathrm{m} / \mathrm{z}): 528\left(\mathrm{M}^{+}+1\right), 526\left(\mathrm{M}^{+}+1\right), 524\left(\mathrm{M}^{+}+1\right)$. 


\section{Acknowledgment}

V.K.S. thanks CSIR for a research grant. We also thank CSIR, New Delhi for a Senior Research Fellowship to B.A.B.P.

\section{References}

1. Heathcote, J.; Hibbert, J. 'Aflatoxins, Chemical and Biological Aspects', Elsevier, Oxford, 1978.

2. Barton, D.H.R.; Chung, H.T.; Gross, A.D.; Jackman, L.M.; Martin-Smith, M. J. Chem. Soc. 1961, 5061.

3. (a) Snider, B.B.; Hui, R.A.H.F. J. Org. Chem. 1985, 50, 5167. (b) Toni, S.; Inokuchi, T.; Yukawa, Y. J. Org. Chem. 1885, 50, 5875. (c) Mehta, G.; Rao, H.S.P.; Reddy, K.R. J. Chem. Soc. Chem. Commun. 1987, 78. (d) Vader, J.; Koopmans, R.; Ae. De Groot,; van Veldhuizen, A.; van der Klerk, S. Tetrahedron 1988, 44, 2663. (e) Piruung, M.C.; Zhang, J.; McPhill, A.T. J. Org. Chem. 1991, 56, 6269.

4. (a) Ueno, Y.; Moriya, O.; Chino, K.; Wtanabe, M.; Okawara, M. J. Chem. Soc. Perkin Trans. 1 1986, 1351. (b) Pflieger, D.; Muckensturm, B. Tetrahedron Lett. 1987, 28, 1519. (c) Pirrung, M.C.; Chang, V.K.; DeArnicis, C.V. J. Am. Chem. Soc. 1989, 111, 5824. (d) Dumas, S.; Ghosez, L.; Hesbain-Frisque, A.; Marko, I.; Ransmans, B. J. Am. Chem. Soc. 1985, 107, 2129.

5. Butterworth, J. H.; Morgan, E. D. J. Chem. Soc. Chem. Commun. 1968, 23.

6. (a) Anderson, J. C.; Ley, S. V.; Santafianos, D.; Sheppard, R. N. Tetrahedron 1991, 47, 6813. (b) Ley, S. V. in Bioactive compounds from plants, Chadwick, D. J.; Marsh, J. (Eds). Ciba Foundation Symp. 154, Wiley, Chichester. 1990, 80.

7. Nishikimi, Y.; Iimori, T.; Sodeoka, M.; Shibasaki, M. J. Org. Chem. 1989, 54, 3354.

8. (a) Ley, S. V.; Denholm, A. A.; Wood, A. Nat. Prod. Rep. 1993, 109 and references cited therein. (b) Ley, S. V.; Santafianos, D.; Blaney, W. M.; Simmonds, M. S. J. Tetrahedron Lett. 1987, 28, 221.

9. Gelas, J.; Horton, D. Heterocycles 1981, 16, 1587.

10. Foster, A. B.; Overend, W. G.; Stacey, M.; Wiggins, L. F. J. Chem. Soc. 1949, 2542.

11. Henry, Jr., K. J.; Fraser-Reid, B. J. Org. Chem. 1994, 59, 5128.

12. For recent reviews on the free radicals in organic synthesis, see: (a) Hilton, S. T.; Ho, T. C. T.; Pljevaljcic, G.; Schulte, M.; Jones. K. Chem. Commun. 2001, 209. (b) Ishibashi, H.; Kato, I.; Takeda, Y.; Kogure, M.; Tamura, O. Chem. Commun. 2000, 1527. (c) Kizil, M.; Patro, B.; Callaghan, O.; Murphy, J. A.; Hursthouse, M. B.; Hibbs, H. J. Org. Chem., 1999, 64, 7856. (d) Ryu, I.; Sonoda, N.; Curran, D. P. Chem. Rev. 1996, 96, 177. (e) Giese, B.; Kopping, B.; Gobel. T.; Dickhaut, J.; Thoma, G.; Kulicke, K. J.; Trach, F. Org. React. 
(N.Y.) 1996, 48, 301. (f) Curran, D. P. Synthesis. 1988, 417 (g) Giese, B. Radicals in Organic Synthesis: Formation of Carbon-Carbon Bonds, Pergamon Press, Oxford, 1986.

13. a) Hanessian, S. The Total Synthesis of Natural Products: The Chiron Approach, Pergamon Press Ltd., 1983. (b) Ogura, H.; Hasegawa, A.; Suami, T. (Eds.) Carbohydrates-Synthetic Methods and Application in Medicinal Chemistry, Kodansha Ltd.; Tokyo 1992.

14. a) Whistler, R. L.; Wolform, M. L. (Eden.) Methods in Carbohydrate Chemistry. 1963, 2, 403-418. (b) For the reduction using Zinc dust and 1-methylimidazole, see: Somak, L.; Iidike, N. J. Carbohydrate. Res. 1993, 12, 679.

15. Schou, C.; Pederson, E. B.; Nielsen, C. Acta Chem. Scand. 1993, 47, 889.

16. Moufid, N.; Chapleur, Y. Tetrahedron Lett. 1991, 32, 1799.

17. (a) Gomez, A. M.; Lopez, J. C.; Fraser-Reid, B. J. Org. Chem. 1995, 60, 3859. (b) Woltering, T. J. Tetrahedron. 1995, 51, 7389. (c) Mesmaeker, A. D.; Hoffmann, P.; Ernst, B. Tetrahedron Lett. 1988, 29, 6585. (d) Audin, C.; Lancelin, J. -M.; Beau, J. -M. Tetrahedron Lett. 1988, 29, 3691.

18. For radical additions on nitriles under the irradiating conditions, see: Wolff, S.; Agosta, W. C. J. Org. Chem. 1978, 43, 3627. (b) For the synthesis of ketones from nitriles using $\mathrm{Mn}(\mathrm{OAc})_{3}$, see: Snider, B. B.; Buckman, B. O. J. Org. Chem. 1992, 57, 322. (c) See also Corey, E. J.; Pyne, S. G. Tetrahedron Lett. 1983, 24, 2821.

19. Chenera, B.; Chuang, C.-P.; Hart, D. J.; Hsu, L.-Y. J. Org. Chem. 1985, 50, 5409.

20. Aldrich Catalog Handbook of Fine Chemicals, India 2002-2003, 1625 